\title{
João 21: indícios para a reconstituição de movimentos do Cristianismo Primitivo
}

\section{John 21: clues for a reconstitution of movements of the Early Christianity}

\section{Juan 21: pistas para la reconstitución de los movimientos del Cristianismo Primitivo}

\author{
Prof. Dr. Paulo Roberto Garcia* \\ Submetido em: 2-4-2021 \\ Aceito em: 10-5-2021
}

\author{
Universidade Metodista de São Paulo \\ Doutor em Ciências da Religião pela \\ Universidade Metodista de São Paulo (Umesp) \\ paulo.garcia@metodista.br
}

\begin{abstract}
RESUMO
O capítulo 21 do Evangelho de João, reconhecido como um apêndice do Evangelho, é geralmente entendido como a explicação da morte do discípulo amado. Essa morte trouxe um trauma para a comunidade que esperava a volta de Jesus antes da morte dele. Esse capítulo, contudo, mais do que explicar a morte de João, o discípulo amado, nos apresenta indícios que nos permitem reconstituir processos importantes na formação do cristianismo primitivo, inclusive a aproximação das comunidades que se reuniam debaixo da autoridade de João (que chamamos de comunidades de memória joanina) das comunidades que se reuniam debaixo da autoridade de Pedro (comunidades de memória petrina). O capítulo 21 apresenta uma aproximação da tradição joanina das tradições sinóticas, sua releitura e a constituição de bases para que os cristãos e as cristãs joaninos passassem a aceitar a liderança petrina e integrarem o cristianismo de memória petrina.

Palavras-chave: Cristianismo primitivo; cristianismo de memória joanina; cristianismo de memória petrina; Evangelho de João.
\end{abstract}

\begin{abstract}
The Chapter 21 of the Gospel of John, recognized as an appendix to the Gospel, is generally understood to explain the death of the beloved disciple. This death brought trauma to the community that was waiting for Jesus to return before his death. This chapter, however, more than explaining the death of John, the beloved disciple, presents us with indications that allow us to reconstruct important processes in the formation of primitive Christianity, including the approximation of the communities that gathered under the authority of John (which we call John). communities of Joanine memory) of the communities that met under the authority of Peter (communities of Petrine memory. Chapter 21 presents an approximation of the Joanine tradition to the synoptic traditions, its reinterpretation and the constitution of bases for the Christians and Christians to pass to accept Petrine leadership and integrate Petrine Christianity.

Keywords: Primitive Christianity; Christianity oh Joanine memory; Christianity of Petrine memory; Gospel of John.

\section{RESUMEN}

El capítulo 21 del Evangelio de Juan, reconocido como un apéndice del Evangelio, se entiende generalmente para explicar la muerte del discípulo amado. Esta muerte trajo trauma a la comunidad que esperaba que Jesús regresara antes de su muerte. Este capítulo, sin embargo,
\end{abstract}


más que explicar la muerte de Juan, el discípulo amado, nos presenta indicios que nos permiten reconstruir procesos importantes en la formación del cristianismo primitivo, incluida la aproximación de las comunidades reunidas bajo la autoridad de Juan (que llamamos Juan). comunidades de memoria de juanina) de las comunidades que se reunieron bajo la autoridad de Pedro (comunidades de memoria petrina). El capítulo 21 presenta una aproximación de la tradición joánica a las tradiciones sinópticas, su reinterpretación y la constitución de las bases para que cristianos y cristianos joánicos lleguen a aceptar el liderazgo petrino e integrar el cristianismo petrino.

Palabras clave: Cristianismo primitivo; Cristianismo de memoria juanina; Cristianismo de memoria petrina; Evangelio de Juan.

\section{Introdução}

O capítulo 21 tem marcado a pesquisa do Evangelho de João. Esse capítulo é reconhecidamente um apêndice. Uma das justificativas para a presença desse apêndice foi a necessidade de explicar a morte de João, a qual provocou uma crise nas concepções teológicas da comunidade. Acreditava-se que João não morreria antes da volta de Jesus. Diante da morte, foi necessário reinterpretar um dito de Jesus que a comunidade havia interpretado como prova de que Jesus voltaria antes da morte de João.

Nossa abordagem nesse artigo, sem desconsiderar a interpretação apresentada acima, é a de que ele oferece indícios que permitem reconstituir etapas da formação do cristianismo primitivo a partir dos diversos movimentos que o compuseram.

Nessa perspectiva esse capítulo apresenta caminhos para compreender tanto a influência da tradição sinótica no evangelho de João (em especial na pesca maravilhosa) como também o processo que levou o evangelho à canonização. Para tanto, vamos iniciar com alguns pressupostos para, em seguida, abordar o texto do capítulo 21.

\section{Pressupostos}

\section{Movimentos do Cristianismo Primitivo}

Em primeiro lugar, estamos usando cristianismo primitivo no singular por opção de valorizar o autoentendimento que esses movimentos tinham. Havia uma pluralidade de comunidades que se entendiam como cristianismo e não como um grupo à parte. Essa opção também prioriza a coalizão das diversas expressões, que é um dos pressupostos desse artigo, como apresentaremos a seguir.

A pluralidade dos movimentos intracristianismo já pode ser percebida nos primeiros escritos do Novo Testamento: as cartas paulinas. Em 1Co 1.12, lemos: "Refiro-me ao fato de cada um de vocês dizer: "Eu sou de Paulo", 
'Eu sou de Apolo', 'Eu sou de Cefas', 'Eu sou de Cristo'". ${ }^{1}$ Isso nos mostra que, desde o início do movimento cristão, grupos surgiram em torno das lideranças carismáticas. Mostra também que, em alguns momentos, se digladiaram em torno das concepções firmadas nas memórias das lideranças, as quais eles seguiam. Nesse artigo, nos interessam dois deles: os seguidores de João e os seguidores de Pedro.

O cristianismo de memória petrina, que inicialmente teve uma forte presença na Galileia e Síria, expandiu-se, ligou-se e ganhou predominância sobre o cristianismo de memória paulina. Desta forma, esse movimento, que no futuro se tornará a memória oficial do cristianismo, assume a gentilidade do movimento paulino e acrescenta a tradição judaico-cristã da região siro-galilaica.

O movimento joanino, originalmente localizado na região da Transjordânia, migrou para a Ásia, tendo em Éfeso um centro importante. As características desse movimento iremos detalhar mais abaixo.

\section{O capitulo 21 - um apêndice}

Como afirmamos acima, assumimos que o capítulo 21 é um apêndice. Em Jo 20.30-31, encontramos uma primeira conclusão do Evangelho: "Na verdade, Jesus fez diante dos seus discípulos muitos outros sinais que não estão escritos neste livro. Estes, porém, foram registrados para que vocês creiam que Jesus é o Cristo, o Filho de Deus, e para que, crendo, tenham vida em seu nome". Jo 21.24-25 irá repetir, em parte, essa conclusão: "Este é o discípulo que dá testemunho a respeito destas coisas e que as escreveu; e sabemos que o seu testemunho é verdadeiro. Há, porém, ainda muitas outras coisas que Jesus fez. Se todas elas fossem relatadas uma por uma, penso que nem no mundo inteiro caberiam os livros que seriam escritos". O que chama a atenção é que, nessa conclusão, há uma afirmação da autoridade da memória registrada pelo discípulo que testemunhou tudo o que foi escrito. A informação "e sabemos" mostra que a memória desse capítulo já está mediada pelos seguidores do "discípulo que dá o testemunho".

\section{João 21 - um capítulo enigmático}

O texto de João 21 costura duas narrativas que cumprem o papel de aproximar duas lideranças de movimentos do cristianismo primitivo: João e Pedro.

A primeira cena (Jo 21.1-14) narra a pesca maravilhosa. A segunda cena (Jo 21.15-23) narra a refeição após a pesca. Uma vez mais, temos a apro-

1 As citações bíblicas, exceto quando necessário apresentar uma tradução própria, seguirão a tradução da Nova Almeida Atualizada. 
ximação das duas lideranças, Pedro e João, desta feita em um processo de concessão de autoridade de conduzir o rebanho entregue para Pedro.

O conjunto dessas duas narrativas nos permite reconstituir uma etapa da história do movimento joanino, mais precisamente a aproximação desse grupo dos movimentos que iriam se constituir no cristianismo que definiu o cânon do Novo Testamento e as doutrinas da igreja.

\section{João 21.1-14: a pesca maravilhosa e João - aquele que reconhece Jesus}

A primeira narrativa desse apêndice retoma uma tradição muito forte das memórias dos evangelhos sinóticos: a pesca maravilhosa. $\mathrm{Na}$ virada do $1^{\circ}$ para o $2^{\circ}$ século, período em que esse apêndice foi redigido, essa narrativa estava vinculada ao chamado vocacional dos discípulos. Isso é percebido na forma em que Evangelhos Sinóticos a utilizam nas cenas de vocação dos discípulos.

Encontramos a vocação de Pedro, Tiago e João em Mateus 4.18-22, Marcos 1.16-20 e Lucas 5.1-11. Os 3 relatos sinóticos, e também o relato de João, se localizam junto ao mar da Galileia (Mateus e Marcos), lago de Genesaré (Lucas) e mar de Tiberíades (João). Nomes diferentes para um mesmo lugar. Em Mateus, Marcos e Lucas a vocação é de Pedro, Tiago e João. No texto de João, encontramos como personagens "Simão Pedro, Tomé, chamado Dídimo, Natanael, que era de Caná da Galileia, os filhos de Zebedeu e mais dois discípulos de Jesus" (Jo 20.2). Um primeiro destaque é que a presença de Pedro, Tiago e João acontece em todos os textos. O nome dos filhos de Zebedeu não são citados, mas isso pode ser compreendido a partir de uma característica do Evangelho, de acordo com a qual o nome João não é usado. Quando o Evangelho se refere a João, usa a expressão "discípulo amado".

Uma primeira percepção, ao comparar esses quatro relatos, se dá em torno da localização geográfica e desses personagens que se repetem. São relatos que preparam a vocação de Pedro e dos discípulos.

Outro destaque que precisamos fazer ao comparar esses relatos se dá em termos da diferença do Evangelho de Lucas com os Evangelhos de Mateus e Marcos. Lucas insere nesse relato a narrativa da pesca maravilhosa. Ou seja, há uma vinculação do Evangelho de Lucas entre a pesca e a vocação. A recepção do texto de Marcos por Lucas ou insere a memória da pesca maravilhosa na narrativa da vocação de Pedro, Tiago e João ou consolida uma memória que já era corrente e que havia unido essas duas narrativas. $\mathrm{Na}$ memória lucana, pesca e vocação se constituem em uma unidade de memória da comunidade.

A pesca maravilhosa em João não quebra a lógica da unidade pesca e vocação. Pedro será vocacionado após a refeição, que é a segunda cena desse 
capítulo. Porém, temporalmente em relação ao ministério de Jesus, o Evangelho de João deslocará essa narrativa do início do ministério de Jesus para os encontros entre os discípulos e o ressuscitado, uma releitura das memórias da vocação de Pedro. Nos processos finais da redação do Evangelho de João há uma presença de características da linguagem lucana. Uma está no capítulo 21 e a outra no capítulo 8 (o relato da mulher adúltera).

Aqui, temos uma primeira aproximação das memórias dessa comunidade com a tradição sinótica. Porém, essa pesca é localizada nesse relato como um evento pós-pascal. Ou seja, ela passa a ser uma das experiências de encontro com o ressuscitado.

A cena da pesca se encerra com uma afirmação de ser essa a terceira vez que Jesus se manifestava entre eles após a ressurreição (v. 14). O destaque é que há o encerramento, mas, imediatamente no versículo seguinte, a história é retomada, agora com a refeição. Assim, percebemos que as duas narrativas dialogam em torno da aparição do ressuscitado.

$\mathrm{Na}$ pesca maravilhosa, encontramos alguns elementos típicos dos textos de memória joanina. Eles nos apontam como a comunidade recebeu histórias presentes nos sinóticos e como as retrabalharam dentro de conceitos típicos dos escritos de memória de João.

Uma característica dos escritos de memória joanina é a proximidade do discípulo amado de Jesus e a capacidade que ele tem de reconhecer Jesus. No capítulo 13, na refeição do lava-pés, Jesus anuncia que será traído:

Depois de dizer isso, Jesus se angustiou em espírito e afirmou:

— Em verdade, em verdade lhes digo que um de vocês vai me trair.

Então os discípulos olharam uns para os outros, sem saber a quem ele se referia.

Ao lado de Jesus estava reclinado um dos seus discípulos, aquele a quem ele amava.

Simão Pedro fez um sinal a esse, para que perguntasse a quem Jesus se referia. Então aquele discípulo, reclinando-se sobre o peito de Jesus, perguntou:

— Senhor, quem é? (Jo 13.21-25).

No texto, dois destaques. O primeiro é a proximidade do discípulo amado a Jesus. O segundo é que ele é um intermediador entre Jesus e os discípulos. Em um texto pertencente às comunidades que se identificavam como seguidoras da memória joanina - Atos Apócrifos de João - encontramos:

Assim, depois de ter conduzido o navio para terra, observamos como ele nos ajudou a manter o barco nas amarras. Quando saímos daquele lugar com a intenção de segui-lo, ele voltou a aparecer quase calvo, mas com uma barba espessa e grossa. Mas para Tiago (ele se mostrou) como um jovem imberbe. Nós dois nos perguntamos, perplexos, o que essa visão significaria. Então, como os dois seguiram, pouco a pouco (aumentou) 
a nossa perplexidade quando refletimos sobre o que aconteceu. Entretanto, o que me pareceu mais estranho foi o seguinte: tentei observá-lo mais em particular, e nunca pude ver seus olhos fechados, mas sempre abertos. Muitas vezes ele apareceu para mim como um homem pequeno e feio, totalmente como alguém que sempre olha para o céu com o rosto. Também eu tinha outra coisa maravilhosa: quando estávamos à mesa debrucei-me no peito e pressionava contra mim. Às vezes sentia doce e terno, e outras vezes duro como pedras, enquanto eu estava perplexo e disse dentro de mim:

$\mathrm{O}$ que isso significa para mim? E enquanto eu estava remoendo isso em minha mente ... (PIÑERO, CERRO, 2004, p. 335, tradução nossa).

Nesse texto, como em outros de Atos Apócrifos de João, mesmo Jesus aparecendo em manifestações polimórficas, João sempre reconhece o Senhor. Mais que isso, nessas aparições a percepção que João tem de Jesus é de um adulto, enquanto Tiago vê um jovem. João não apenas reconhece Jesus como também o vê como adulto, mostrando a maturidade da fé do apóstolo.

Ao abordar esse texto, queremos destacar que os movimentos do cristianismo primitivo que se identificavam como herdeiros da memória joanina compartilham dessa ideia em comum. As perícopes de João 21.15-23, embora não de forma explícita, deixa subentendido que Jesus aparece polimorfo. No meio da refeição, aparece a seguinte afirmação: "Nenhum dos discípulos ousava perguntar: 'Quem é você?', porque sabiam que era o Senhor” (Jo 21.12b). Jesus não é fisicamente reconhecido pelos discípulos. O mesmo acontece na pesca maravilhosa. Os discípulos não reconhecem Jesus (v. 4). Porém, após a pesca do grande número de peixes, João afirma para Pedro: "É o Senhor".

Diante de um Jesus não reconhecido pelos discípulos, João não só é o que tem o discernimento de quem é o desconhecido, identificando o Senhor, como também comunica isso explicitamente para Pedro. Isso possibilita o encontro de Pedro com Jesus.

$\mathrm{Na}$ conclusão da primeira narrativa, encontramos um momento singular na tradição joanina, a ênfase na partilha do alimento. Diferentemente dos sinóticos, o Evangelho de João não apresenta a consagração dos alimentos, a eucaristia, como central na última refeição. Deste modo, os eventos que envolvem o alimento não têm no Evangelho a mesma importância da tradição sinótica. Porém, nesse capítulo, o alimento exerce um papel central em torno da refeição propiciada por Jesus.

Essa primeira perícope nos oferece alguns indícios ${ }^{2}$ que permitem, em diálogo com a segunda perícope, reconstruir situações dos movimentos do

2 O conceito de leitura indiciária é usado a partir da perspectiva de Carlo Ginzburg. Os conceitos são trabalhados de modo mais sistematizado em dois livros: Mitos, emblemas e sinais (1990) e O fio e os rastros (2007). Esse último livro faz um balanço de seu pensamento. 
cristianismo primitivo. Em primeiro lugar, uma aproximação entre as memórias joaninas com as narrativas sinóticas. A pesca maravilhosa, um texto comum da tradição sinótica, é relido nesse capítulo. Seu papel nos Evangelhos sinóticos, ligado à vocação dos discípulos, será fio condutor à vocação de Pedro, tema da próxima perícope, a refeição com os discípulos. Em segundo lugar, ao ligar esse relato às memórias joaninas, em especial à capacidade de João de reconhecer Jesus mesmo quando Ele está em forma que impede os discípulos de reconhecê-lo, mostra uma aproximação das memórias e, consequentemente, dos grupos.

Aqui, caminhamos diferentemente de alguns autores que não enxergam nesse texto a presença de dois grupos antagônicos. Pedro e João são interpretados nessa perícope como ações colaborativas e não como representantes de grupos antagônicos (BLANE, 2007, p. 158-160). Nossa perspectiva é que essa perícope aproxima, na construção de novas narrativas, grupos que eram antagônicos e, em determinado momento, se aproximaram. Isso é o que veremos na segunda narrativa.

\section{Jo 21.15-23 - Pedro, apascentador e pastor das ovelhas e cordeiros}

A segunda narrativa gira em torno de Pedro. As pesquisas em torno dessa perícope focam com muita ênfase as três perguntas feitas por Jesus (com alterações no verbo amar) e as respostas de Pedro (marcado pelo uso do verbo fileo - amor filial, amizade). Entendemos que essas observações são relevantes, mas, para esse artigo, vamos focar nas ordens de Jesus para Pedro. As ordenanças de apascentar e pastorear cordeiros e ovelhas são palavras de transmissão de autoridade. Pedro, nesse texto, recebe a autoridade de conduzir o rebanho. A pergunta fundamental é: por que, em um texto da comunidade joanina, em especial em um apêndice ao evangelho, a figura de Pedro aparece recebendo a autoridade de Jesus para conduzir o rebanho? Aqui temos um ponto importante para uma reconstrução do cristianismo primitivo, onde há uma aproximação entre o cristianismo de memória joanina e o cristianismo de memória petrina. ${ }^{3}$

A redação do capítulo 21 aconteceu em um tempo em que Pedro e João já estavam mortos. Ou seja, esse capítulo mostra de um lado a crise da comunidade diante da morte de alguém que na expectativa dela estaria vivo quando Jesus voltasse e, de outro lado, a aproximação com o movimento pe-

\footnotetext{
3 Nesse ponto, muitos pesquisadores apontam que esse capítulo é o resultado da aproximação da comunidade joanina da petrina. Porém, um argumento para isso se dá no campo político. A autoridade de Pedro é tão forte que se torna necessário respeitá-la (veja, por exemplo, BLANE, 2007, p. 179-182; 1238-9).
} 
trino, que também estava consolidado após a morte do Apóstolo. A narrativa relê essas mortes e o significado delas para a vida de fé. Por isso, a morte de Pedro é descrita como o cumprimento da palavra de Jesus que ele seria levado aonde não gostaria de ir. Isso aponta a tradição em que Pedro teria sido crucificado (de cabeça para baixo); esses versículos são lidos como uma alusão à crucificação (REED, 2007, p. 104). O que queremos apontar é que o drama da morte de uma liderança da comunidade se associa a uma situação de violência do império, que matou a liderança de uma comunidade da qual esses seguidores do discípulo amado se aproximam (REED, 2007, p. 106).

\section{Última cena - explicação da morte de João}

O capítulo se encerra com a explicação da morte de João, apresentando a tese de que a morte antes da volta de Jesus foi uma expectativa criada a partir de um mal-entendido sobre as palavras de Jesus. A frustração e o drama decorrente dela são compreensíveis, uma vez que a volta imediata de Jesus fazia parte do imaginário cristão do primeiro século. Paulo afirmou em sua carta aos Tessalonicenses: "Porque o Senhor mesmo, dada a sua palavra de ordem, ouvida a voz do arcanjo e ressoada a trombeta de Deus, descerá dos céus, e os mortos em Cristo ressuscitarão primeiro; depois, nós, os vivos, os que ficarmos, seremos arrebatados juntamente com eles..." (1Ts 4.16s, grifo nosso). Também a comunidade judaico-cristã de Jerusalém organizou uma escala de venda de bens para sobreviverem dessa venda até que Jesus voltasse (ver Atos 1-5). Não é de se estranhar que a comunidade joanina tenha desenvolvido a mesma expectativa ou sofrido a mesma frustração.

O problema que envolve essa frustração não se dá só no campo da fé. Como apontamos no texto de Atos, a expectativa da volta iminente de Jesus provocou uma postura de vida diferenciada diante do mundo. Uma vez que Jesus voltaria logo, não seria necessário cultivar os campos, constituir família, se preocupar com as situações de injustiça do mundo ao redor, etc. Ao perceber que a volta não seria tão iminente quanto se esperava, as comunidades precisaram ressignificar sua pertença no mundo e seu relacionamento com ele, reorganizando a vida na perspectiva da continuidade. Como cristãos e cristãs vão organizar suas vidas, planos, famílias e a própria sobrevivência nas sociedades onde elas estão inseridas? Aqui se insere a mensagem do capítulo 21. Ao corrigir a interpretação equivocada, a comunidade necessitará se aproximar de outros movimentos cristãos na busca da continuidade e viabilidade da vida. Os cristãos e cristãs petrinos estão mais bem inseridos nesse mundo. Se encontraram com os grupos paulinos e estão se estabelecendo e interagindo com o cotidiano de forma mais organizada. O testemunho 
das deuteropaulinas (1 e 2 Timóteo e Tito) mostram isso. Esses grupos se organizaram e conseguiram ressignificar sua relação com o mundo.

A comunidade joanina, frente à necessidade de reorganizar sua existência e sua pertença ao mundo romano do qual ela faz parte, vai encontrar nas comunidades de memória petrina um caminho para sua continuidade. Diante disso, a costura entre a autoridade de Pedro e a importância de João torna-se necessária. Não é um processo racional ou politicamente engendrado. É uma construção de narrativa que ressignifica as convicções frente ao novo momento que elas enfrentam. Koster afirma:

As concepções do Evangelho de João deixaram uma marca decisiva na história daquelas comunidades especiais da Síria de influência joanina, como pode ser deduzido do desenvolvimento subsequente dos eventos. O próprio evangelho foi submetido, logo após sua redação, a outra redação que o aproximou um pouco mais da teologia do restante da cristandade síria, ou seja, do reconhecimento explícito da autoridade de Pedro (Jo 21) e da aceitação de uma escatologia e de uma doutrina sacramental mais alinhada com as concepções das comunidades sírias. (KOSTER, 1988, p. 712 - tradução nossa). ${ }^{4}$

A partir dessa afirmação de Koster, o capítulo 21 nos permite entender os motivos que levaram a essa revisão de conceitos e mudança de postura dos integrantes dessa expressão cristã de memória joanina.

\section{João 21 - indícios para reconstrução de movimentos cristãos primitivos}

A abordagem do capítulo 21 visando encontrar indícios para a reconstrução do cristianismo primitivo nos leva a nos deparamos com um momento ímpar na caminhada de comunidades cristãs primitivas: o encontro de comunidades de memórias diferentes que se fundem na busca da continuidade de sua existência frente aos desafios do mundo dominado pelos romanos, marcado por contradições e sistemas que colocam a vida em risco e, mais que tudo, um mundo no qual necessitarão continuar existindo por mais tempo que inicialmente imaginavam.

Desse modo, cristãos e cristãs de memória joanina, vivendo na Ásia, vão se aproximar das tradições petrinas e, assim, as memórias joaninas se agregarão ao amplo espectro de tradições cristãs que o movimento petrino está consolidando. Ao se estudar o Evangelho de João, é comum afirmar que

\footnotetext{
4 Helmut Koster localiza a tradição joanina na Síria. Preferimos localizar as memórias joaninas nessa etapa da vida da comunidade que estamos abordando, localizando-a na Ásia, provavelmente Éfeso. Veja discussão em BRONW, 2002, p. 485.
} 
a aproximação da tradição sinótica garantiu a canonização desses escritos. Aqui, essa conclusão é parecida com os manuais de teologia que apontam a aproximação da tradição sinótica como possibilitadora da canonização do evangelho, mas caminha por outra rota. A canonização dos escritos joaninos se dá devido a esse processo de encontro e fusão de movimentos de memória petrina e joanina. O resultado desse processo é a continuidade da existência das memórias joaninas agora como parte do grande espectro de tradições cristãs que transitam em um movimento que vai se consolidando e se firmando debaixo da autoridade petrina.

O capítulo 21, portanto, se constitui em um relato que nos permite vislumbrar a complexidade do cristianismo primitivo em sua consolidação e em sua conformação no mundo de tradição greco-romana, dominado pelos romanos no primeiro século.

\section{Referências bibliográficas}

ARENS, Eduardo. Ásia Menor nos tempos de Paulo, Lucas e João: aspectos sociais e econômicos para compreensão do Novo Testamento. São Paulo: Paulus, 1997.

ASHTON, John. The Gospel of John and Christian origins. Minneapolis: Fortress, 2014.

ASHTON, John. Understanding the Fourth Gospel. 2. ed. Oxford: Oxford University Press. 2007.

BERGER, Klaus. As formas literárias do Novo Testamento. Trad. Fredericus Antonius Stein. São Paulo: Loyola, 1998.

BLAINE, Bradford B., Jr. Peter in the Gospel of John: the making of an authentic disciple. Leiden: Brill. 2007.

BRODIE, Thomas L. The Gospel according to John: a literary and theological commentary. Oxford: Oxford University Press. 1993.

BROWN, Raymond E. Introducción al Nuevo Testamento. Vol. 1: Cuestiones preliminares, evangelios y obras conexas. Madrid: Trota. 2002.

BROWN, Raymond Edward. A comunidade do discípulo amado. 6. ed. São Paulo: Paulus, 2011.

BROWN, Raymond Edward. Introdução ao Novo Testamento. São Paulo: Paulinas, 2004.

BULTMANN, Rudolf. Teología del Nuevo Testamento. Trad. Victor Abelardo Martinez de Lapera. 4. ed. Salamanca: Sígueme, 2001.

CHEVITARESE, André Leonardo; CORNELLI, Gabriele. Judaísmo, cristianismo, helenismo: ensaios sobre interações culturais no Mediterrâneo antigo. Itu: Ottoni Editora, 2003.

CONZELMANN, Hans. Gentiles, Jews, Christians: polemics and apologetics in the Greco-Roman Era. Translation of M. Eugene Boring. Minneapolis: Fortress Press, 1992, p. 135-233.

CROSSAN, Dominic John. O nascimento do cristianismo: o que aconteceu nos anos que se seguiram à execução de Jesus. São Paulo: Paulinas, 2004.

GARCIA, Paulo Roberto. Unção - uma disputa no cristianismo primitivo. Conflitos e rup- 
turas na comunidade joanina. In: ALMEIDA, Maria Aparecida A.; DIAS CHAVES, Júlio César; FUNARI, Pedro Paulo Abreu (org.). A espiritualidade no Cristianismo Primitivo - As muitas faces do Gnosticismo. São Paulo: Fonte Editorial, 2019, p. 209-234.

GINZBURG, Carlo. Mitos, emblemas, sinais: morfologia e história. São Paulo: Companhia das Letras, 1990.

GINZBURG, Carlo. O fio e os rastros: verdadeiro, falso, fictício. São Paulo: Companhia das Letras, 2007.

IZIDORO, José Luiz. O problema da identidade no cristianismo primitivo: interação, conflitos e desafios. Oracula, São Bernardo do Campo, v. 4, n. 7, p. 53-65, 2008.

KEENER, Craig S. The Gospel of John: a commentary. Grand Rapids: Baker Academic, 2003.

KÖSTER, Helmut. Introducción al Nuevo Testamento: historia, cultura y religión de la época helenística e historia y literatura del cristianismo primitivo. Salamanca: Sígueme, 1988.

LIMA JUNIOR, Francisco Chagas Vieira. Circularidade cultural e resistência simbólica no cristianismo primitivo: os relatos evangélicos sobre o nascimento de Jesus e o culto ao imperador romano. Espaço Acadêmico, Maringá, v. 9, n. 102, p. 124-133, 2009.

ORTON, David E. (ed.). The composition of John's Gospel. Selected studies from Novum Testamentum. Leiden: Brill. 1999.

REED, David. Rethinking John's social setting: hidden transcript, anti-language, and the negotiation of the Empire. Biblical Theology Bulletin: Journal of Bible and Culture, Cambridge, v. 36, n. 3, p. 93-106, 2006.

SIMON, Marcel; BENOIT, André. Judaísmo e cristianismo antigo: de Antíoco Epifânio a Constantino. São Paulo: Editora da Universidade de São Paulo, 1987.

THATCHER, Tom. John's memory theater: the Fourth Gospel and ancient mnemo-rhetoric. Catholic Biblical Quarterly, Washington, DC, v. 69 n. 3, p. 487-505, 2007.

THEISSEN, Gerd. A religião dos primeiros cristãos: uma teoria do cristianismo primitivo. Trad. Paulo F. Valério. São Paulo: Paulinas, 2009. 